\title{
«PAX..!» DE RUBÉN DARÍO: TESTAMENTO POÉTICO Y ACTO DE CLAUSURA
}

\author{
NIALL BINNS \\ Universidad Complutense de Madrid
}

\section{Resumen}

Se analiza el carácter inaugural de la obra de Rubén Darío, pero sobre todo la conciencia que el nicaragüense tenía de estar, sucesivamente, iniciando y clausurando etapas - el parnasianismo, el simbolismo, etc.- en la historia de la poesía en lengua española. Esta capacidad inaugural entra en crisis después de la publicación en 1905 de Cantos de vida y esperanza. En 1914, el comienzo de la Gran Guerra precipitó el adiós a Europa de Darío y la redacción de su poema «¡Pax...!», que se deja leer como un acto de clausura no solo de la obra y vida del poeta, sino de toda una época de la poesía en lengua española.

Palabras clave: Rubén Darío, literatura de la primera guerra mundial, «¡Pax...!»

\begin{abstract}
This is a study of Rubén Darío's inaugural capacity, but particularly of the awareness he had of his role in initiating and closing, one after the other, different stages - Parnassianism, Symbolism, etc. - in the history of poetry in Spanish. This inaugural capacity fell into a crisis after the publishing in 1905 of Cantos de vida y esperanza. In 1914, the outbreak of the Great War prompted Darío's farewell to Europe and the writing of his poem «¡Pax...!», which can be read as the act of closure both of the poet's life and works and of a whole period of Spanish-language poetry.
\end{abstract}

Keywords: Rubén Darío, First World War literature, «¡Pax...!» 
Las aclamadas fechas de centenarios y de fastos no hacen que este hombre solitario sea menos que un hombre. Jorge Luis Borges ${ }^{1}$

1.

Pocos poetas han sido tan conscientes de su papel de iniciador como Rubén Darío. Se recordará que no tuvo pudor al exaltar, en su prefacio a Cantos de vida y esperanza, el «movimiento de libertad que me tocó iniciar en América» y que se había propagado, triunfando, hasta Europa (2011: 405). Creo que la capacidad inaugural de Darío se combina en su obra con una habilidad única —aprendida en el camino- de cerrar y clausurar tanto sus libros como los movimientos y hasta las épocas literarias que él tenía plena conciencia de estar encabezando y encarnando.

Véase, si no, la manera en que aprovechó los elogios de Juan Valera publicados en El Imparcial sobre Azul... para crear un nuevo envoltorio para la segunda edición del libro, enmarcando esta entre las dos cartas del español como prólogo — con su celebración, a pesar suyo, del galicismo mental de Darío- y los musculosos, esculturales textos de los «Sonetos áureos» del final —entre ellos los dedicados a Caupolicán y a Venus_ junto a otros seis sonetos, los «Medallones» liderados por homenajes a los dos maestros del Parnaso francés, Leconte de Lisle y Catulle Mendès, y a Walt Whitman, el único poeta americano que había alcanzado ese renombre universal que el nicaragüense ya exigía para sí mismo. Enmarcado así, contundente como una joya, se dejaba Azul... para la posteridad como la obra magna del parnasianismo en lengua española.

Pero Darío quemaba etapas, y en 1891, año de esa segunda edición de Azul..., ya emprendía el camino del simbolismo. La forma de enmarcar Prosas profanas, cinco años más tarde, mostraría a las claras esta modulación en su trayectoria. De las palabras liminares, destacan los dos modelos clave: ¡Verlaine!, un nombre susurrado «en mi interior» después de la extensa lista de influencias ineludibles, y otra vez Whitman, el «demócrata» de la América del

1. Los versos de Borges provienen del poema «Sarmiento», de su libro El otro, el mismo (1969). El Seminario «Textos esenciales de Rubén Darío», celebrado en la Universidad de Alicante del 4 al 6 de mayo de 2016, fue ejemplar a la hora de evitar la fastuosa banalidad que acecha siempre en las «aclamadas fechas de centenarios». Reclamó y ofrendó el estudio minucioso de poemas concretos del nicaragüense. En el presente texto -menos minucioso, por cierto, que la mayoría-, he procurado mantener la oralidad de la conferencia que presenté. 
Norte, erigido como contrapunto definitivo de Darío, que se presentaba como el poeta de una Latinoamérica orgullosamente mestiza —la «nuestra América» de Martí-, alguien que sería incapaz de cantar como Whitman a un presidente de la República y que se autorretrataba como la antítesis aristocrática del poeta estadounidense mediante su insistencia temática en «princesas, reyes, cosas imperiales», pero sobre todo con sus «manos de marqués» (326). Prosas profanas se iniciaba y se cerraba con los dos poemas más palpablemente simbolistas del libro: el primero, "Era un aire suave...», en el que el poeta seguía - como recordaría más tarde en Historia de mis libros- «el precepto del Arte Poética de Verlaine: 'De la musique avant toute chose'» (Darío, 1988: 64); el último, separado como único poema de la sección homónima, era «El reino interior». Tan delicadamente envuelto, Prosas profanas se ufanaba de ser la obra magna, ahora, del simbolismo francés trasladado a la lírica española, una obra prodigiosa - no hace falta decirlo- en sus matices sensoriales y cromáticos.

Después de otros cinco años, sin embargo, irreprimible y ya instalado en Europa, Darío se encaminaba de nuevo por nuevos rumbos. Ya no quería ser simplemente el gran simbolista en lengua española. De ahí que en la segunda edición de Prosas profanas, de 1901, cambiara de envoltorio, inaugurándola con el prólogo de José Enrique Rodó - con esa notoria reticencia inicial que decía: «indudablemente, Rubén Darío no es el poeta de América»—y cerrándola con un poema que cuestionaba todos los hallazgos del libro - y claro, si hay un libro pletórico de hallazgos en la lengua, es Prosas profanas-, con ese signo de interrogación encarnado en el cuello del «gran cisne blanco» y dirigido específicamente al propio autor. Este soneto final hacía constar el fracaso de la búsqueda estética emprendida ( «o persigo una forma que no encuentra mi estilo») y, además, mostraba ese fracaso plasmándolo en el primer y último titubeo musical del libro, en un verso que se atasca al llegar a la cesura, un verso que para un lector del siglo Xx se resiste a moldearse al ritmo alejandrino del poema ( $i$ «-no-há-llo-si-nó // la-pa-lá-bra-que-hú-ye»?), y que exige más bien fracturar la armonía tan majestuosamente sostenida en todos los poemas anteriores y ser leído como un intruso, como un discorde endecasílabo: «Y-no há-llo-sí-no-la-pa-lá-bra-que hu-ye» (2011: 400-401).

En 1905, llegan los Cantos de vida y esperanza, que Darío vuelve a presentar en un envoltorio de una eficacia notable, con esa plena conciencia que tenía del camino recorrido que cerraba, del camino nuevo que inauguraba. Ahí están el breve "prefacio» y el poema inicial, «Yo soy aquel que ayer no más decía...», en el que el poeta se distanciaba de sus libros y estéticas anteriores (del «verso azul» y la «canción profana», de la torre de marfil y ese mundo 
«muy siglo XVIII»), anunciaba su incursión en temas políticos —incluido un canto a un presidente de República- e insinuaba el tono nuevo que exploraría en los poemas mayores del poemario, arraigados en el paso de los años y en «las sombras de mi propio abismo» (407-408). El cierre del libro, por su parte, apunta hacia nuevos rumbos para el explorador e iniciador hasta entonces insaciable que era Darío. El penúltimo poema, «Allá lejos», abría las puertas hacia una poesía que volvería a los lares nicaragüenses de su infancia; y el último, «Lo fatal» (471), compendio de los temores existenciales ya concentrados en los dos «Nocturnos» del libro, escenificaba en la forma misma del poema los efectos corrosivos de una angustia ya plenamente moderna y urbana. A partir del quinto verso («Ser, y no saber nada, y ser sin rumbo cierto»...), no hay más que una larga enumeración, sin verbo principal que los coordine, de motivos avasalladores para la angustia, para condenar al yo a la intemperie espiritual; la segunda estrofa, además, se clausura con el encabalgamiento más brutal de la historia de la poesía — «y sufrir por la vida y por la sombra y por»-, como si autor y lector quedaran colgados, de la mano, sobre un abismo ahora «muy siglo XX», privados del sustento de la Razón, de Dios y del Arte; y de la misma manera en que la segunda edición de Prosas profanas se cerrara con ese aborto de un alejandrino, «y no hallo sino la palabra que huye», los alejandrinos de «Lo fatal» se desarticulan al final en un eneasílabo ( «y no saber adónde vamos»), en un heptasílabo («ni de dónde venimos»), en puntos suspensivos... y el resto es silencio. En un golpe de poeta visionario, Darío había metido un pie y medio en ese colosal derrumbe de las certidumbres y las formas que sería, una década más tarde, la Vanguardia.

Pero no se atrevió. El Darío más grande - el que iniciaba y clausuraba etapas en la historia de la poesía - termina precisamente con estos poemas finales de 1905. Se encontraría, por los motivos que fuesen, incapaz de avanzar por los rumbos esbozados en ellos. De hecho, en su libro siguiente, El canto errante, recordaría «Lo fatal» con suma ligereza, en un divertimento titulado «Eco y yo», como si no hubiese sido más que un simple capricho esa caída abismal en el sinsentido. Decía:

Lo fatal con sus ardientes dientes

apretó mi conmovida vida;

mas me libró, en toda parte, Arte. (543)

A partir de 1907, rehuir esos ardientes dientes era más apremiante para Darío que seguir explorando. Sus cuarenta años le pesaban y lo cierto es que cada 
uno de sus nuevos libros tendría algo o mucho de miscelánea; varios de los poemas potencialmente más innovadores («Epístola a la señora de Leopoldo Lugones», «Agencia...») tienen más de divertimento que de búsqueda; otros son poemas notoriamente de ocasión o reiteraciones desvaídas de textos anteriores; y unos pocos, piezas sueltas, brillan, sí, como aisladas obras maestras, como el fascinante e inaugural «Metempsicosis» —rescatado de sus primeros años en Buenos Aires-, o las magistrales indagaciones en la vejez que son «Poema del otoño»y «La Cartuja». Pero son pocos. Tal vez el último de esos grandes y dispersos poemas finales sea «iPax...!», un extenso texto de Darío, de 1914, que es, a su manera, un poema de clausura, el adiós a una vida y una obra ya concluidas o a punto de concluir, el adiós a la vez a una época de la historia.

2.

En su fracturación de las bellas formas en los poemas finales de Prosas profanas y Cantos de vida y esperanza, Darío se había asomado - acaso sin darse cuenta de ello- al siglo XX recién estrenado. Pero conviene recordar, si seguimos las ideas de Eric Hobsbawm y otros, que el siglo XX no se puso en marcha de verdad hasta los inicios de la Gran Guerra, es decir, hasta el año 1914. Y en 1914 nos centraremos ahora.

Ya lo sabían los piramidólogos y numerólogos anglosajones del siglo XIX, cuando descifraron en esa gran «Biblia en piedra» que era la pirámide egipcia de Guiza, que el año clave, el año en que se iban a revelar a la humanidad todos los secretos, era 1914. Así, por ejemplo, el pionero de los Testigos de Jehová Charles Taze Russell anunció en 1876 —después de medir minuciosamente todos los pasajes ascendentes y descendientes de la gran pirámideque 1914 sería el año que pusiese fin a los «tiempos de los gentiles» y al reinado de los «hombres imperfectos». Y en su libro Millennial Dawn. Volume II: The Time is at Hand (1889), vaticinaba que en ese mismo año de 1914, Cristo vendría por segunda vez a la tierra para imponer el Reino de Dios «sobre las ruinas de sus instituciones actuales» (Gaustad y Noll, 2003: 284).

No salieron las cosas como preveía el pobre Charles Taze Russell, pero el 28 de junio de 1914 el estudiante serbio Gavrilo Princip asesinó de un disparo, en la ciudad de Sarajevo, al archiduque Franz Ferdinand de Austria, dando cuerda en el acto a la Gran Guerra y al «breve siglo XX» que, de acuerdo con Hobsbawm, duraría desde 1914 hasta la disolución de la Unión Soviética en 1991. La guerra del 14 precipitó el fin de la civilización occidental del siglo XIX, una civilización capitalista, liberal, burguesa y eurocéntrica, excesivamente orgullosa de sí misma, demasiado confiada en el avance de sus saberes, 
su ciencia y su progreso material y moral. Con el disparo de Gavrilo Princip, esa civilización se agrietó y procedió a caerse en pedazos, desencadenando una carnicería sin parangón en la historia de los pueblos, pavimentando el camino hacia el periodo histórico que Hobsbawm bautizaría como la «Edad de los Extremos» (1995: 2-11): una edad durante la cual no solo Europa sino el mundo entero se verían condenados a vivir, sucesivamente, la Gran Depresión, la Guerra Civil Española, la Segunda Guerra Mundial y las largas décadas de la Guerra Fría.

En fin, el año de inflexión en la historia del mundo fue 1914. Lo fue, también, en la historia de la poesía.

\section{3.}

Cada esfuerzo por fijar períodos en la literatura hace agua, pero 1914 es una fecha tan buena como cualquiera para cerrar la gran época del Modernismo. Olivier Compagnon, en su libro América Latina y la gran guerra, añadió como subtítulo: «El adiós a Europa» (2014). Pues en el otoño de 1914, con el ejército alemán ya atrincherado a setenta kilómetros al este de París, Rubén Darío, horrorizado, dijo un adiós precipitado a Europa, abandonando la capital francesa y embarcando en Barcelona el 25 de octubre con rumbo a Estados Unidos. Llevaba consigo los primeros cuarenta y cuatro versos de su poema «Pax...!», que terminaría semanas más tarde en el Hotel Earlington de Nueva York (Beardsley, 1967: 10-13).

Darío estrenaría este poema, el 4 de febrero de 1915, en un acto antibélico organizado en la Universidad de Columbia por el Institute of Arts and Sciences y la Hispanic Society of America. Lo anunció, en el recital, así:

SEÑORAS, SEÑORES: Voy a dar lectura a un poema de Paz, en medio de tantos ecos de guerra. Encontraréis en él un marcado carácter religioso, lo cual queda bien en este inmenso país, que a pesar de sus vastas conquistas prácticas y de su constante lucha material, es el único en el mundo que tiene un Thanksgiving Day. Sé que para algunas gentes, como decía el famoso M. de Buloz, director de la Revue des Deux Mondes, Dios no es de actualidad. Yo creo, sin embargo, en el Dios que anima a las naciones trabajadoras, y no en el que invocan los conquistadores de pueblos y destructores de vidas, Atila, Dios $\&$ Comp. Limited. A medida que la ciencia avanza, el gran misterio aparece más impenetrable, pero más innegable. Un Poincaré, un William James y un Bergson, son los pioneers del infinito. En cuanto a un ambiente de eternidad, Edgar Pöe, que solamente ha escrito unas dos veces, en toda su obra, el nombre de Cristo, adopta una definición de Dios tomada de Granwill [sic], quien seguramente recordó a Santo Tomás: Dios no es sino una gran Voluntad que penetra todas las cosas por la naturaleza de su intensidad... Yo creo en ese Dios.

He aquí el poema que voy a tener la honra de leeros. (9-10) 
El poema contaba con 194 versos en su versión manuscrita leída en Nueva York, a la cual se añadirían los cuatro versos finales cuando se publicó por primera vez de modo no fragmentario, en una colección póstuma de Baladas y canciones editada en Madrid por Andrés González Blanco, en 1923 (13-15). Encabezado por un verso de Petrarca — «Io vo gridando pace, pace, pace!»- y pautado por una irregular rima consonante, «PPax...!» despliega una polimetría que en sí misma manifiesta la confusión y consternación del poeta ante lo que pasaba en el mundo: en los 44 versos escritos en Europa hay 7 heptasílabos, 9 octosílabos, 11 eneasílabos, 1 decasílabo, 8 endecasílabos, 1 dodecasílabo y 7 alejandrinos.

Aquí no hay, ni puede haber armonía, y el poema se pone en marcha con esa contradicción del poeta obligado, al igual que Petrarca, a enunciar a gritos una palabra hecha para ser susurrada: pace, pace, pace... En una anticipación febril de La decadencia de Occidente de Oswald Spengler, que se publicaría en el año final de la Gran Guerra, Darío contrapone desde el inicio de su poema la «tierra antigua» europea, abrumada por la sangre y el llanto, a «los países de la Aurora» americana a la que dirige sus gritos. Esta separación de los continentes y sus destinos, que volverá en las últimas estrofas de « $\mathrm{Pax} \ldots$ !.», se deja de lado, a continuación, para indagar en una civilización sometida al regreso cíclico de la violencia, al choque sin fin entre las fuerzas bélicas, por un lado, y por otro las fuerzas de la religión, el arte y cultura, que desde siempre se habían esforzado por comprender y registrar la guerra, y además, habían profetizado la llegada de un juicio final que se hacía presente por fin, en 1914, en esa guerra que pondría fin a todas las guerras (Darío, 2011: 822).

Presente y pasado se contrastan y se hermanan a la vez. El ayer se resucita para comprender el hoy. Donde Cristo regó lágrimas y estrellas, manda ahora la Muerte; pero la interpretación supersticiosa de la muerte de un Papa o el nacer de un cometa - el cometa Halley, de 1910, sin duda- equipara el presente con el año mil, y la hecatombe de la guerra se compara con la Torre de Babel bíblica desmoronándose «al estampido del cañón y del fusil». Petrarca, la Biblia y ahora Horacio se aprestan para dar sentido al presente. «Bellaque matribus detestata» (y las guerras detestadas por las madres), decía el poeta latino en la primera de sus Odas, aunque Darío desplaza la alusión materna — sin sacarnos de la antigüedad clásica — para proferir una maldición no a las guerras en sí sino a la diosa que las amparaba, Palas Atenea, «madre negra (...) odiosa a las dulces mejillas», y proclama su convicción de que ella —diosa estéril, a fin de cuentas- sucumbirá a una sabiduría que no le pertenece, al «trueno de oro de las ideas». Los versos que siguen parecerían animar precisamente a construir, frente a las armas, una barricada hecha del legado secular 
de la escritura y el arte: «Amontonad las bibliotecas, / poblad las pinacotecas, / con los prodigios del pincel / y del buril y del cincel». El imperativo y la brevedad contundente de estos versos encarnan un espíritu de combate, pero el ímpetu no tarda en deshacerse. El verso siguiente alude a los grandes - al Homero de la guerra de Troya, al Vinci de las invenciones bélicas, al Dante que pobló de guerreros su Purgatorio y su Infierno-, pero se trata no de convocarlos como aliados, sino de evocarlos simplemente como testigos del «espectáculo cruel / desde el principio hasta el fin», es decir, de la violencia que ha imperado en el mundo desde el asesinato de Abel por Caín hasta el fratricidio humano de 1914. Hay que recordarlo: el Darío que escribía «¡Pax...!» era un poeta prematuramente envejecido, alcoholizado, achacoso y abierto a todos los temores y tentaciones de la fe, y para él el único realmente capaz de actuar —no solo de ver y registrar- era Aquel anunciado por el Apocalipsis de San Juan, que pronto arribaría «vencedor y envuelto en fuego» para poner orden en «nuestro siglo eléctrico y ensimismado» (823).

La fascinación apocalíptica estaba ya arraigada en la obra de Darío desde Cantos de vida y esperanza. Recuérdense los versos de "Canto de esperanza»: «¿Ha nacido el apocalíptico Anticristo?» (423); o los de «Mientras tenéis, oh, negros corazones...»: «Un gran Apocalipsis horas futuras llena, / iya surgirá vuestro Pegaso Blanco!» (424). Siguió en El canto errante, en la «Salutación al Águila»: «Águila que estuviste en las horas sublimes de Pathmos. / [...] / Por algo estás presente en los sueños del Apocalipsis» (495). Y se prolongó, en 1910, en Poema del otoño y otros poemas, en «Santa Elena de Montenegro»: «Hora de Cristo en el Calvario, / hora de terror milenario, / hora de sangre, hora de osario. / [...] / Van rebaños dolientes... Van / visiones de duelo y afán / cual vio en su apocalipsis Juan» (577-578).

Comentando esta obsesión apocalíptica de Darío, Juan Larrea —en su ensayo «Vaticinio de Rubén Darío»— habló de esas «postrimerías que ocasionaban los terrores de Rubén», afirmando que «la insistencia con que a partir de cierta época de su vida se repiten a lo largo de su obra las alusiones al Apocalipsis de San Juan revela que, en su sentir, esta inminente catástrofe se emparentaba con el final de un ciclo: aquel a que corresponde la revelación del

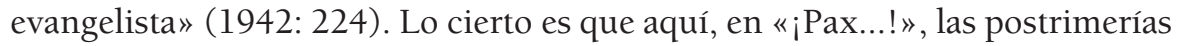
se ven tanto en las alusiones al «Libro del Abismo» de San Juan —con la lluvia de llama y veneno, con Abbadon, Appollion y Exterminans-, como en las profecías del santo irlandés Malaquías —moduladas por Verlaine- y en las imágenes visionarias de Albert Durero, Jacques Callot y Goya (824).

El tono profético, cargado de elementos apocalípticos y amparado también por el «Vidente de Francia» Víctor Hugo, surge en el poema a raíz de las 
noticias que llegaron a Darío, mientras seguía en Europa, de la destrucción llevada a cabo por naciones «ciegas a Dios» pero que «a Dios invocan», naciones que dando la espalda al Cristo que «es la Luz, el Camino y la Vida», avanzaban a gritos de «iGuerra Santa!». Por culpa de ellas, «y en el nombre de Dios, / casas de Dios de Reims y de Lovaina / las derrumba el Obús 42...» (823-824). En efecto, durante los primeros meses de la guerra el ejército alemán, empleando morteros de asedio de $42 \mathrm{~cm}$. de las fábricas armamentísticas de Gustav Krupp, llamados «Dicke Bertha» —es decir, «Berta la Gorda»provocó estragos en los frentes belgas y franceses (Zabecki, 2015: 110). A finales de agosto de 1914, los alemanes saquearon e incendiaron la Iglesia de Saint Pierre y la biblioteca de la Universidad de Lovaina, y en la ofensiva del 19 y 20 de septiembre de 1914, con los obuses de Berta la Gorda, asolaron la catedral de Reims. Sacrilegio, para Darío.

Por eso, este no dudaba en señalar a quién era, para él, el responsable: al Kaiser Wilhelm, de la dinastía Hohenzollern, emperador de Alemania desde el año 1888. «Hohezollern: está sobre tu frente / un águila de oro» (824). En estrofas posteriores, «¡Pax...!» alude explícitamente al industrialista Gustav Krupp — «Krupp hace el crudo espanto que a Thánatos alegra»- y compara al Kaiser al rey sacrílego de Babilonia, Baltasar, y a su sucesor Darío «el medo»:

Cual Baltasar o Darío, Guillermo

mira con ojo enfermo

de visiones de siglos

un gran tropel de espantables vestiglos.

Y el casco que lo cubre,

la capa que le viste,

bajo el blancor de la nieve insalubre,

y el bigote erizado,

y el aspecto cesáreo y el aire de soldado,

y toda esa potencia, tienen algo de triste.

Y al llegar las ternuras de Noël,

Santa Claus, el que viene a la cuna del niño,

tuvo que recoger su túnica de armiño

por no mancharse en tanta sangre y tanta hiel (826).

Hacia el final del poema, leyendo la escritura críptica inscrita sobre la pared de la Historia, Darío fragua su propia profecía. Y no es casual, justo después de estos versos dedicados al Kaiser, que recupere la armonía de las formas regulares. En ocho tercetos encadenados, decasílabos dactílicos monorrimos cerrados con el serventesio de rigor, recuerda al Víctor Hugo que en la guerra francoalemana de 1870 contó cómo en la Noche Buena se unieron los dos 
ejércitos, desde ambas orillas del Sena, en un canto navideño, primero en francés desde la orilla izquierda, y luego en alemán: «Y en la noche profunda de guerra, / Jesucristo, que el odio destierra, / por el canto echó el mal de la tierra». En el serventesio final, Darío plantea la pregunta clave para entender su poema y su fe en el futuro:

¿No habrá alguno de raza más joven

que, rompiendo a la guerra su yugo, pueda unir el poder de Beethoven con el canto que dio Víctor Hugo?

(827).

Esa voz capaz de fundir armoniosamente las fuerzas de Beethoven y de Hugo debía provenir de una «raza más joven», y en los 34 alejandrinos que clausuran el poema, Darío, después de reiterar el impulso destructivo y autodestructivo de la vieja Europa, vuelve a dirigirse a los países de la Aurora — de la Aurora americana: esa «raza más joven»— a los que invocó al comienzo. El apocalipsis desembocaba no en el fin del mundo, sino en el fin de una época histórica - la época del Anticristo- centrada en Europa, dominada y ahora dinamitada por Europa. En cambio, la nueva época surgida de la destrucción sería liderada precisamente por los países del Nuevo Mundo. Por eso, al repudiar los horrores que había visto en Europa, Darío apela a las repúblicas americanas, pidiéndoles que eviten el camino de la guerra, y recordando a los héroes de la Independencia que lucharon a favor de la Patria, la Libertad y la Paz:

¡Oh pueblos nuestros! ¡Oh pueblos nuestros! iJuntaos

en la esperanza y en el trabajo y la paz!

No busquéis las tinieblas, no persigáis el caos,

y no reguéis con sangre nuestra tierra feraz.

Ya lucharon bastante los antiguos abuelos por Patria y Libertad, y un glorioso clarín clama a través del tiempo, debajo de los cielos,

Washington y Bolívar, Hidalgo y San Martín. (828)

El ejemplo de una Europa diezmada por la guerra debía servir como estímulo para que se diera lugar en América a ese reinado de «los puros hombres de buena voluntad» anunciado por el caballo blanco del Apocalipsis (825), y al sueño panamericano que Darío había cantado — de manera tan polémica - en Río de Janeiro en 1906, y que renovaba ahora, entre Europa y Nueva York, en las últimas semanas de 1914:

Ved el ejemplo amargo de la Europa deshecha;

ved las trincheras fúnebres, las tierras sanguinosas;

y la Piedad y el Duelo sollozando los dos.

No; no dejéis al odio que dispare su flecha, 
llevad a los altares de la Paz, miel y rosas.

Paz a la inmensa América. Paz en nombre de Dios.

Y pues aquí está el foco de una cultura nueva, que sus principios lleva desde el Norte hasta el Sur, hagamos la Unión viva que el nuevo triunfo lleva; The Star-Spangled Banner, con el blanco y azur...

4.

Y ahora, un breve colofón. Darío abandonó Europa en 1914, aterrado por la barbarie de la guerra y la decadencia del Viejo Mundo, y regresó a América, en plena huida, primero a Estados Unidos, luego a Guatemala (donde lo ampararía el Señor Presidente Manuel Estrada Cabrera) y por último a Nicaragua, donde moriría — cerrando el envoltorio de su vida- en los brazos de su mujer Rosario, de la que llevaba décadas intentando escapar.

Como testamento poético de su adiós a Europa, dejó este canto apocalíptico de esperanza que es «¡Pax...!». Pero Europa era mucha Europa, y París mucho París. No es extraño, por tanto, que dos años más tarde, con Darío ya muerto, cruzara el Atlántico con rumbo a Francia Vicente Huidobro, adalid de una nueva escritura y pletórico de planes y dinero para invertir en sus proyectos. Arribó a un país donde acababa de terminar, en la región de Picardie, la atroz batalla del Somme, y donde seguía librándose, en Lorraine, la batalla de Verdun. Aún faltaban casi dos años para el final de la guerra, pero Huidobro se instaló en París - en medio del bullicio cultural de una retaguardia extrañamente plácida y cosmopolita - hasta que a finales de marzo de 1918 una inesperada ofensiva alemana avanzara tan rápida e inesperadamente que 183 obuses cayeron sobre la capital. Aterrado — como Darío cuatro años antes- fugó hacia el Sur, y en Madrid inauguró una nueva época de la poesía en lengua española con los libros Poemas árticos y Ecuatorial. Como el poema «Pax...!», son libros imbuidos en la experiencia de la guerra y con un lenguaje y un imaginario netamente apocalípticos. En ellos, no obstante, nada quedaba de ese ampuloso tono decimonónico y victorhuguesco de Darío. La época del nicaragüense había concluido. Estos eran tiempos de una nueva poesía, capaz de responder en sus propias formas a todas las fracturas y rupturas de la modernidad. Y en el mismo año de 1918, de manera menos ostentosa pero no por ello sin importancia, nació otra de las líneas fundamentales de la poesía del siglo Xx cuando el nicaragüense Salomón de la Selva, primer traductor de «¡Pax...!», se alistó tardíamente en el ejército británico y escribió a partir de las experiencias que en realidad no llegó a vivir en la guerra - como ha mostrado recientemente, en un libro fascinante, Steven F. White (2016: 
91) - un poemario fantasiosamente testimonial pero innovador en su notorio coloquialismo: El soldado desconocido, de 1922.

\section{Bibliografía citada}

BeARdSley, JR., Theodore S. Beardsley, «Rubén Darío and the Hispanic Society: the Holograph Manuscript of ¡Pax!», Hispanic Review, XXXV: 1 (enero de 1967), pp. 1-42.

Compagnon, Olivier, América Latina y la Gran Guerra. El adiós a Europa (Argentina y Brasil, 1914-1939), Buenos Aires, Crítica, 2014.

DARío, Rubén [1916], Historia de mis libros, Managua, Editorial Nueva Nicaragua, 1988.

- Obra poética, ed. de José Carlos Rovira Soler, Madrid, Fundación José Antonio de Castro, 2011.

DE la SElVA, Salomón, El soldado desconocido, México, Cultura, 1922.

GAUSTAD, Edwin S. y Mark A. Noll (eds.), A Documentary History of Religion in Ameria since 1877 [1983], Grand Rapids (Michigan), William B. Eerdmans Publishing Company, 2003.

Hobsbawm, Eric, The Age of Extremes. The Short Twentieth Century (1914-1991), Londres, Abacus, 1994.

LARrEA, Juan, «Vaticinio de Rubén Darío», Cuadernos Americanos, I: 4 (July/ August, 1942), pp. 213-238.

White, Steven F. Rubén Darío y Salomón de la Selva: ecos de la muerte y la guerra, León, Promotora Cultural Leonesa, 2016.

ZABECKI, David. T., «German Artillery in the First World War», en Sanders Marble (ed.), King of Battle: Artillery in World War I, Boston, Brill, 2015, pp. 101-125. 


\section{Anexo I: «iPax...!», de Rubén Darío}

Io vo gridando pace, pace, pace!

Así clamaba el italiano, así voy gritando yo ahora, «alma en el alma, mano en la mano», a los países de la Aurora...

En sangre y llanto está la tierra antigua.

La Muerte, cautelosa, o abrasante, o ambigua, pasa sobre las huellas del Cristo de pies sonrosados que regó lágrimas y estrellas. La Humanidad, inquieta, ve la muerte de un Papa y el nacer de un cometa: como en el año mil. Y ve una nueva Torre de Babel desmoronarse en hoguera cruel, al estampido del cañón y del fusil.

Matribus detestata! Madre negra a quien el ronco ruido alegra de los leones; Palas, odiosa a las dulces mejillas, puesto que das las flechas y las balas: ¡abominada seas por los corrientes siglos y fugaces edades, porque, a pesar de todo, tus fuertes potestades sucumbirán al trueno de oro de las ideas!

Amontonad las bibliotecas, poblad las pinacotecas, con los prodigios del pincel y del buril y del cincel.

Haced la evocación de Homero, Vinci, Dante, para que vean el espectáculo cruel desde el principio hasta el fin: la quijada del rumiante en la mano de Caín sobre la frente de Abel.

Pero el misterio vendrá, vencedor y envuelto en fuego, más formidable que lo que dirá

2. Rubén Darío, Obra poética, ed. de José Carlos Rovira Soler, Madrid, Fundación José Antonio de Castro, 2011, pp. 821-828. 
la épica india y el drama griego.

Y nuestro siglo eléctrico y ensimismado, entre fulgurantes destellos,

verá surgir a Aquel que fue anunciado

por Juan el de suaves cabellos.

Todo lo que está anunciado

en el Gran Libro han de ver las naciones,

ciegas a Dios, que a Dios invocan en preñado

tiempo de odios y angustias y abominaciones.

Y lo que Malaquías el vidente

vio en la Edad Media — «enorme y delicada»,

según dice Verlaine-, verá la gente,

hoy en sangre deshecha y desastrada.

Se grita: ¡Guerra Santa!,

acercando el puñal a la garganta

o sacando la espada de la vaina:

y en el nombre de Dios,

casas de Dios de Reims y de Lovaina

las derrumba el Obús 42...

¡No, reyes!... Que la guerra es infernal, es cierto;

cierto que duerme un lobo

en el alma fatal del adanida;

mas también Jesucristo no está muerto,

y contra el homicidio, el odio, el robo,

¡Él es la Luz, el Camino y la Vida...!

Hohenzollern: está sobre tu frente

un águila de oro.

Yo recuerdo el poema del Vidente

de Francia, el vivo cántico sonoro

en donde la justicia al bronce intima...

Dios está sobre todo; y en la cima

de las montañas de la gloria humana,

de pronto un ángel formidable anima

la testa loca del divino trueno,

y de las urnas de las sombras mana

lluvia de llama y lluvia de veneno;

y Abbadon, Appollion, Exterminans — que es el mismo-

surge de entre las páginas del Libro del Abismo.

Emperadores, Reyes, Presidentes: la hora

llegará de la Aurora.

Pasarán las visiones de Durero,

pasarán de Callot los lansquenetes,

los horrores de Goya el visionario,

en la memoria amarga de la tierra. 
Pasará de la guerra el tigre fiero, se olvidarán obuses y mosquetes, y ante la sacra sangre del Calvario se acabarán las sangres de la guerra.

Púrguese por el fuego

y por el terremoto

y por la tempestad

este planeta ciego,

por los astros ignoto

como su pasajera Humanidad.

Y puesto que es preciso,

vengan a purgar este

planeta de maldad,

con la guerra, la peste

y el hambre, mensajeras de Verdad.

De la Verdad que hace secar las fuentes, y en la gehenna rechinar los dientes.

Si la Paz no es posible, que como en Isaías las ciudades revienten;

que sean de tinieblas las noches y los días;

que las almas que sienten

soplos de Dios, duerman sueño profundo

mientras que se desangra y se deshace el mundo...

Y que cuando del apocalíptico enigma

surja el caballo blanco, con resplandor y estigma,

los únicos que se hundan en la santa Verdad

sean los puros hombres de buena voluntad,

que entre las zarzas ásperas de este vivir, han visto

las huellas de los pasos de Nuestro Padre Cristo.

¡Ah, cuán feliz el demonio perverso,

odio imperante en todo el universo,

odio en el mar y debajo del mar;

odio en la tierra firme y en el viento,

y sangre y sangre que pueda llegar

a salpicar el mismo firmamento!

Se animaron de fuego y de electricidad

los Behemothes y Leviathanes.

En la bíblica inmensidad

no vieron más los Isaías y los Juanes.

Cual Baltasar o Darío, Guillermo

mira con ojo enfermo

de visiones de siglos

un gran tropel de espantables vestiglos.

Y el casco que lo cubre, 
la capa que le viste,

bajo el blancor de la nieve insalubre,

y el bigote erizado,

y el aspecto cesáreo y el aire de soldado,

y toda esa potencia, tienen algo de triste.

Y al llegar las ternuras de Noël,

Santa Claus, el que viene a la cuna del niño,

tuvo que recoger su túnica de armiño

por no mancharse en tanta sangre y tanta hiel.

$* * *$

Era en 1870.

Francia ardía en su guerra cruenta.

Hugo en versos soberbios lo cuenta.

Y París, la divina, en su pena,

a las fiestas usuales ajena,

solo sombra ve en su Nochebuena.

Y era el sitio, y el hambre, y la furia,

y el espanto, y el odio, y la injuria.

Todo muerte, o incendio, o lujuria.

En un lado del Sena está lista

la tremenda alemana conquista;

y en el otro, la Francia imprevista.

Dan las doce -la mágica hora, que presagia una mística auroralas campanas de Nuestra Señora.

Y en la orilla izquierda del Sena, en la sombra nocturna resuena un noël de ritual Nochebuena.

Un silencio. Y después, noble, austero, contestó aquel ejército fiero como un grave coral de Lutero.

Y en la noche profunda de guerra, Jesucristo, que el odio destierra, por el canto echó el mal de la tierra.

¿No habrá alguno de raza más joven que, rompiendo a la guerra su yugo, pueda unir el poder de Beethoven con el canto que dio Víctor Hugo?

Vivat Gallia Regina! Vivat Germania Mater!

Esta salutación, que al gran lírico plugo 
¿hace arder esa selva, y rugir ese cráter, y al ángel de la Paz lo convierte en verdugo?

Si la princesa austríaca destroza su abanico, Guillermo en sus palacios entroniza a Watteau, y sabe que la flauta del Grande Federico aún ignoraba el triste requiem de Waterloo.

Mas hay que juzgar siempre, que si es dura la lucha del tigre, del león, del águila en su vuelo; si los hombres guerrean, es porque nadie escucha los clarines de paz que suenan en el cielo.

Krupp hace crudo espanto que a Thánatos alegra; pero el de Asís fue pasmo que el Bajísimo enoja; Húsares de la Muerte deben llevar cruz negra, mientras las dulces gentes de Amor llevan cruz roja.

¡Oh pueblos nuestros! ¡Oh pueblos nuestros! ¡Juntaos en la esperanza y en el trabajo y la paz! No busquéis las tinieblas, no persigáis el caos, y no reguéis con sangre nuestra tierra feraz.

Ya lucharon bastante los antiguos abuelos por Patria y Libertad, y un glorioso clarín clama a través del tiempo, debajo de los cielos, Washington y Bolívar, Hidalgo y San Martín.

Ved el ejemplo amargo de la Europa deshecha; ved las trincheras fúnebres, las tierras sanguinosas; y la Piedad y el Duelo sollozando los dos. No; no dejéis al odio que dispare su flecha, llevad a los altares de la Paz, miel y rosas.

Paz a la inmensa América. Paz en nombre de Dios.

Y pues aquí está el foco de una cultura nueva, que sus principios lleva desde el Norte hasta el Sur, hagamos la Unión viva que el nuevo triunfo lleva; The Star-Spangled Banner, con el blanco y azur... 